\title{
Dechlorane Plus and its dechlorinated analogs from an e-waste recycling center in maternal serum and breast milk of women in Wenling, China
}

\author{
Yu-Jie Ben ${ }^{\mathrm{a}}$, Xing-Hong Li ${ }^{\mathrm{a}, *}$, You-Lin Yang ${ }^{\mathrm{b}}$, Long Li $^{\mathrm{a}}$, Jun-Ping Di ${ }^{\mathrm{b}}$, Wen-Yue Wang ${ }^{\mathrm{a}, \mathrm{c}}$, Ren-Fang Zhou ${ }^{\mathrm{b}}$, \\ Ke Xiao ${ }^{a}$, Mei-Yun Zheng ${ }^{b}$, Yuan Tian ${ }^{c}$, Xiao-Bai Xu ${ }^{\text {a }}$ \\ a State Key Laboratory of Environmental Chemistry and Ecotoxicology, Research Center of Eco-Environment Sciences, The Chinese Academy of Sciences, PO Box 2871, \\ 18 Shuangqing Road, Haidian District, Beijing 100085, People's Republic of China \\ ${ }^{\mathrm{b}}$ First Hospital of Wenling, Taizhou 317004, Zhejiang Province, People's Republic of China \\ ${ }^{\mathrm{c}}$ Beijing Technology and Business University, Beijing 100037, People's Republic of China
}

\section{A R T I C L E I N F O}

\section{Article history:}

Received 12 July 2012

Received in revised form

12 September 2012

Accepted 28 September 2012

\section{Keywords:}

Dechlorane Plus and its dechlorinated

analogs

Breast milk

Serum

E-waste

\begin{abstract}
A B S T R A C T
We measured Dechlorane Plus (DP) and its dechlorinated analogs in the blood and milk from women living in e-waste recycling sites in Wenling of Taizhou region, China $(n=49)$. Both syn-DP and anti-DP were detected in all samples. Another compound, $\mathrm{Cl}_{11}$-DP, was detected in $45 \%$ and $84 \%$ of milk and serum samples, respectively. DP levels in blood and milk from residents living in the local environment $>20$ yrs ( $R_{20}$ group) were significantly higher than those living in Taizhou $<3$ yrs ( $R_{3}$ group $)(p<0.05)$. The milk/serum partition coefficient from the same women was approximately 0.43 and 0.47 for syn-DP and anti-DP, respectively. A similar value in milk compared with anti-DP/ $\sum \mathrm{DPs}\left(f_{\text {anti }}\right)$ in serum suggested that stereoselective DP bio-accumulation did not occur during the DP transport from blood to milk. This result indicate that DP can bio-accumulate in blood and milk with the low milk/serum partition coefficient and similar blood and milk stereoselective bio-accumulation profiles.
\end{abstract}

(C) 2012 Elsevier Ltd. All rights reserved.

\section{Introduction}

Dechlorane Plus (DP, $\mathrm{C}_{18} \mathrm{H}_{12} \mathrm{Cl}_{12}$ ) is a high production volume chemical with an annual global production of approximately 10 million pounds (Gauthier and Letcher, 2009). As an additive flame retardant, DP has been widely used in electrical wire and cable coating, computer and television's connectors, and plastic roofing materials for almost 50 years (Sverko et al., 2011). Since Hoh et al. first reported the environmental occurrence of DP in 2006 (Hoh et al., 2006), some studies have demonstrated that DP is a global persistent contaminant that bio-accumulates in some environmental media, and is also susceptible to long-range atmospheric transport (Sverko et al., 2011). Owing to these specific properties and as a possible replacement for decabromodiphenyl ether (Commission, 2011), scientists have been prompted to measure current levels of DP and its dechlorinated analogs in the environment and to determine environmental and human health effects. Currently, there are some data on DP in the environment, but there are few data on DP in humans (Xian et al., 2011).

\footnotetext{
* Corresponding author.

E-mail address: lxhzpb@rcees.ac.cn (X.-H. Li).
}

Significantly high levels of flame retardants from electronic/ electrical products such as polybrominated diphenyl ethers (PBDEs), polychlorinated biphenyls (PCBs), polybrominated biphenyls (PBBs), and tetrabromobisphenol A have been found in electronic waste (e-waste) recycling areas (Ni et al., 2010), and ewaste recycling activity is also suspected to be an important source of DP. High DP levels have been detected in aquatic and terrestrial food webs (Wu et al., 2010), dust (Zhu et al., 2007) and human tissue (serum (Ren et al., 2009) and hair (Zheng et al., 2010)) in residents of e-waste recycling facilities in Guiyu, which is an ewaste recycling town in China. Taizhou is another well-known ewaste recycling site in China, and inappropriate e-waste recycling procedures have resulted in serious contamination to its surrounding areas (Ni et al., 2010). Wenling city is one of the major cities involved in e-waste recycling in Taizhou area. Our recent survey on environmental safety and human health in Wenling found that unregulated operations were still widely ongoing. A screening analysis on DP was conducted in some environmental samples from residential areas surrounding e-waste recycling sites, and high concentrations of DP were detected in indoor dust (528.0 $\mathrm{ng} \mathrm{g}^{-1}$, dry weight, [dw]), rice soil (275.7 $\mathrm{ng} \mathrm{g}^{-1}, \mathrm{dw}$ ), hen eggs (49.1 $\mathrm{ng} \mathrm{g}^{-1}$, lipid weight, [lw]), and e-waste crushed particles $\left(43,762.6 \mathrm{ng} \mathrm{g}^{-1}, \mathrm{dw}\right)$ and e-waste burning residues $\left(47.5 \mathrm{ng} \mathrm{g}^{-1}, \mathrm{lw}\right)$ improperly discarded into the environment (unpublished data). 
This suggests heavy DP environmental contamination in Wenling city and the possibility of high body burden in humans.

Levels of persistent organic pollutants (POPs) measured in blood and breast milk are generally used to assess human exposure to contaminants. The partitioning relationship between maternal blood and breast milk can provide important information for understanding pollutant toxicokinetics, and improve estimates from breast milk to maternal blood levels or from maternal blood to breast milk levels (Aylward et al., 2003; Schecter et al., 2010). Concentrations and milk/serum partitioning of some POPs, such as organochlorine pesticides (OCPs), polychlorinated dibenzo-pdioxins and furans (PCDD/Fs), PCBs, and PBDEs have been reported in a few studies (Aylward et al., 2003; Jaraczewska et al., 2006; Wittsiepe et al., 2007; LaKind et al., 2009; Schecter et al., 2010). DP is a relatively new emerging pollutant, and only two published reports on human blood and milk have individually investigated human DP exposure (Ren et al., 2009; Siddique et al., 2012). There are few reports on the dechlorinated analogs of DP in human tissues (Ren et al., 2009; Zheng et al., 2010) and no information concerning DP partitioning between serum and breast milk.

Primitive e-waste recycling operation could impose serious threats to the health of workers and local residents. A study has been conducted on DP in serum from electronics dismantling workers and high levels have been found (Ren et al., 2009). However, information concerning the DP body burdens of local residents at e-waste recycling sites is limited. Thus, this study aimed to characterize exposure levels of DP and its dechlorinated analogs in local residents living in the e-waste recycling site, and assess the partitioning relationship between serum and breast milk from the same woman, and determine the stereoselective DP bioaccumulation profile in blood and milk.

\section{Materials and methods}

\subsection{Sample area}

Taizhou region is located in the center of the coastal area of Zhejiang Province, China $\left(28^{\circ} \mathrm{N}\right.$ latitude and $122^{\circ} \mathrm{E}$ longitude) with a total area of $9411 \mathrm{~km}^{2}$ and a population of 5.9 million. E-waste recycling operations have been ongoing for approximately 30 years in this area. According to the Economic and Trade Commission of Taizhou in 2005, more than 2 million metric tons of e-waste were processed in Taizhou annually, and 40,000 people were employed in the e-waste recycling industry (Chan et al., 2007). Wenling city is one of the major cities involved in e-waste recycling close to the city centre in Taizhou area with a total area of $836 \mathrm{~km}^{2}$ and a population of 1.4 million. A large number of e-waste recycling household workshops have emerged in some villages of Wenling city, partly because of the relatively weak environmental policies. The e-waste recycling operation in the household workshop of Wenling is conducted using crude simple methods, wherein workers burn piles of wires in the open air to remove the cover of metals, melt circuit boards over coal grills to extract valuable chips, and then carelessly stack the useless plastics left after fragmentation around the villages. These primitive operations and weak control on waste products allowed heavy metals and organic contaminants to be easily transferred to the surrounding environment. Therefore, there are serious environmental problems and health risk of workers and local residents arising from e-waste recycling in this area.

\subsection{Sample collection}

Samples were collected from July 2010 to March 2011. Forty-four breast milk samples and 45 serum samples, including 40 breast milk and serum samples from the same women, were collected from mothers in Wenling city of Taizhou area, China. The selected donors were grouped as $R_{20}$ and $R_{3}$ groups in terms of the residential history. For the $R_{20}$ group, the donors, who did not directly participate in e-waste recycling operations, had a $>20$ yrs residential time in some Wenling villages heavily involved in e-waste recycling with a $>10$ yrs history generally. For the $\mathrm{R}_{3}$ group, the donors had resided in Taizhou region for less than three years, who did not live around the e-waste recycling villages and did not also participate in any e-waste recycling activities. Consent forms were signed by the study participants and questionnaire surveys were conducted to acquire personal information, including maternal age at delivery, duration of residency in the local area, height, pre-pregnancy body weight, menarche age, gravida and parity, number of children, education level and occupation. The demographic characteristics of 49 subjects are shown in Table 1. The $R_{20}$ group ( 33 subjects) had a longer resident time than the $R_{3}$ group (16 subjects), with a median of 25 years (range: $20-40$ years) for the former and one year (range: $1-3$ years) for the latter.

Blood sample (approximately $30 \mathrm{~mL}$ ) was collected at delivery using a vacuum system tube, and subsequently centrifuged to obtain maternal serum sample. Serum was then transferred into the hexane-rinsed glass vial. Breast milk sample (approximately $30-50 \mathrm{~mL}$ ) was collected $2-7$ days after delivery using a breast pump with a glass container and transferred to hexane-rinsed glass vial. The samples were kept at $-20^{\circ} \mathrm{C}$ prior to chemical analyses. Simultaneously, five field blanks were prepared with the empty hexane-rinsed glass vials, and five field operational blanks were prepared with hexane-rinsed glass vials filled with $30 \mathrm{~mL}$ distilled water at the sampling sites. Glass vials with Teflon-line screw caps were from Agilent Technologies (Santa Clara, CA, USA) and no targets $\left(\mathrm{Cl}_{10}-\mathrm{DP}, \mathrm{Cl}_{11}-\mathrm{DP}\right.$, anti-DP and syn-DP) were found in the contaminant prescreening process.

\subsection{Chemicals and standards}

Individual solutions of syn-DP $\left(100 \mu \mathrm{g} \mathrm{mL}^{-1}\right)$, anti-DP $\left(100 \mu \mathrm{g} \mathrm{mL}^{-1}\right),{ }^{13} \mathrm{C}_{10}$ syn$\operatorname{DP}\left(100 \mu \mathrm{g} \mathrm{mL}{ }^{-1}\right),{ }^{13} \mathrm{C}_{10}$ anti-DP $\left(100 \mu \mathrm{g} \mathrm{m}^{-1}\right)$ and ${ }^{13} \mathrm{C}_{12}-\mathrm{PCB}-208\left(40 \mu \mathrm{g} \mathrm{mL}^{-1}\right)$ were obtained from Cambridge Isotope Laboratories, Inc. (Andover, MA, USA). $\mathrm{Cl}_{11}$-DP and $\mathrm{Cl}_{10}$-DP solutions $\left(50 \mathrm{mg} \mathrm{mL}^{-1}\right.$ ) were supplied by Wellington Laboratories Inc. (Guelph, ON, Canada). A commercial DP product was supplied by Jiangsu Anpon Electrochemical Co., Ltd. (Huaian city, Jiangsu Province, China). Dichloromethane (J.T. Baker, Deventer, The Netherlands) and n-hexane (Thermo Fisher Scientific, Pittsburgh, PA, USA) were pesticide grade, and other solvents, including methanol and ethanol (Thermo Fisher Scientific), methyl tertiary butyl ether (MtBE) (Tedia Company Inc., Fairfield, OH, USA) and isopropanol (J.T. Baker) were High Performance Liquid Chromatography grade. Silica gel (60-100 mesh) was purchased from Merck KGaA (Darmstadt, Germany) and activated at $550{ }^{\circ} \mathrm{C}$ for $6 \mathrm{~h}$ in a muffle furnace before use.

\subsection{Extraction and cleanup}

The samples were prepared according to a previously described method (Verreault et al., 2005). Breast milk $(3.0 \mathrm{~g})$ or serum $(5.0 \mathrm{~mL})$ was poured into a $50 \mathrm{~mL}$ screw-top centrifuge tube, and spiked with ${ }^{13} \mathrm{C}_{10}$ syn-DP and ${ }^{13} \mathrm{C}_{10}$ anti-DP as the internal standard. First, samples were denatured with $2 \mathrm{~mL}$ of $6 \mathrm{M} \mathrm{HCl}$ and $5 \mathrm{~mL}$ isopropanol, ultrasonically extracted with $20 \mathrm{~mL}$ of $1: 1 \mathrm{MtBE}$ :hexane (v:v) for $7 \mathrm{~min}$, and then separated by centrifugation. The extraction process was repeated three times. The combined extracts were washed with $20 \mathrm{~mL}$ of $1 \% \mathrm{KCl}(\mathrm{w} / \mathrm{v})$ solution, and the organic phase was separated and concentrated. A total of $12 \mathrm{~mL} \times 3$ of $1.0 \mathrm{M} \mathrm{KOH}$ solution was added to the concentrated organic phase (neutral fraction), and then $\mathrm{KOH}$ phase was pooled together and back-washed with $10 \mathrm{~mL}$ hexane

\section{Table 1}

General characteristics of the study participants $(n=49)$.

\begin{tabular}{|c|c|c|c|}
\hline & $\mathrm{R}_{20}(n=33)$ & $\mathrm{R}_{3}(n=16)$ & $p$-value \\
\hline Maternal age at delivery ${ }^{\mathrm{a}}$ (year, \%) & & & $0.148^{\mathrm{b}}$ \\
\hline$<30$ years old & $21(64)$ & $6(40)$ & \\
\hline$\geq 30$ years old & $12(36)$ & $9(60)$ & \\
\hline Pre-pregnancy BMI ${ }^{\mathrm{c}, \mathrm{d}}\left(\mathrm{kg} / \mathrm{m}^{2}\right)(n, \%)$ & & & $0.608^{\mathrm{b}}$ \\
\hline$\leq 21$ & $15(47)$ & $7(54)$ & \\
\hline$>21$ & $18(53)$ & $6(46)$ & \\
\hline Parity $(n, \%)$ & & & $0.500^{\mathrm{b}}$ \\
\hline Primipara & $20(60)$ & 11(69) & \\
\hline Multipara & $14(40)$ & $5(31)$ & \\
\hline Education level $(n, \%)$ & & & $0.598^{\mathrm{b}}$ \\
\hline$\leq 9$ years & $18(55)$ & $10(63)$ & \\
\hline$>9$ years & $15(45)$ & $6(37)$ & \\
\hline Occupation ( $n, \%)$ & & & $0.700^{\mathrm{b}}$ \\
\hline Housewife & $23(70)$ & $12(75)$ & \\
\hline Employee & $10(30)$ & $4(25)$ & \\
\hline Menarche age, year $(n, \%)$ & & & $0.619^{\mathrm{b}}$ \\
\hline$\leq 14$ years old & $21(64)$ & $9(56)$ & \\
\hline$>14$ years old & $12(36)$ & $7(44)$ & \\
\hline Menarche cycle, day $(n, \%)$ & & & $0.235^{\mathrm{b}}$ \\
\hline$\leq 32$ days & $19(58)$ & $12(75)$ & \\
\hline$>32$ days & $14(42)$ & $4(25)$ & \\
\hline Maternal serum lipid (mg/dl) & $0.64 \pm 0.15$ & $0.63 \pm 0.14$ & $0.917^{\mathrm{e}}$ \\
\hline Breast milk lipid (\%) & $1.74 \pm 0.81$ & $1.52 \pm 0.75$ & $0.322^{\mathrm{e}}$ \\
\hline
\end{tabular}


three times. Hexane phase was combined with the neutral organic fraction. The combined neutral extract was dried with anhydrous $\mathrm{Na}_{2} \mathrm{SO}_{4}$ and then concentrated to approximately $1.0 \mathrm{~mL}$. The concentrated neutral extract was transferred to a chromatography column $(30 \mathrm{~cm} \times 10 \mathrm{~mm}$ ID) containing $8 \mathrm{~g}$ silica sulfuric acid (30\% acid by weight) and $2.5 \mathrm{~g}$ of anhydrous sodium sulfate was placed on top of the column. The mixture was then eluted with $50 \mathrm{~mL}$ of dichloromethane: hexane $(1: 1$, $\mathrm{v}: \mathrm{v})$. The eluent was concentrated and adjusted to $20 \mu \mathrm{L}$ for gas chromatographymass spectrometry (GC-MS) analysis. The injection internal standard $\left({ }^{13} \mathrm{C}_{12}\right.$-PCB208) was added prior to gas chromatography-negative chemical ionization-mass spectrometry (GC-NCI-MS) analysis.

\subsection{Instrument analysis}

DP quantification was performed using an Agilent 6890/5973 GC/Mass Selective Detector (MSD) System (Agilent Technologies). The MS analyses were performed in a negative chemical ionization $(\mathrm{NCI})$ mode. The separation was performed using a fused silica capillary column (RTX-1614, $30 \mathrm{~m} \times 0.25 \mathrm{~mm}$ ID and $0.1 \mu \mathrm{m}$ film thickness; Restek Inc. USA). The carrier gas used was helium, with a flow rate of $1.0 \mathrm{~mL} \mathrm{~min}^{-1}$, and methane was used as the reaction gas. The GC oven temperature was programmed as follows: the initial temperature was $100{ }^{\circ} \mathrm{C}$ maintained for $2 \mathrm{~min}$, which was then increased to $250{ }^{\circ} \mathrm{C}$ at a rate of $25^{\circ} \mathrm{C} \mathrm{min}^{-1}$, followed by a $1.5^{\circ} \mathrm{C} \mathrm{min}-1$ ascent to $260{ }^{\circ} \mathrm{C}$, and finally, the temperature was increased at a rate of $25^{\circ} \mathrm{C} \mathrm{min}-1$ to achieve the final temperature of $315^{\circ} \mathrm{C}$, which was maintained for $7 \mathrm{~min}$. The injector, transfer line, and ion source temperatures were 250,280 , and $150{ }^{\circ} \mathrm{C}$, respectively.

Injection of the $1 \mu \mathrm{L}$ of extract was conducted in a pressure-pulsed splitless mode. The ion fragments were monitored as follows: $\mathrm{m} / \mathrm{z} 475.7$ and 477.7 were monitored for ${ }^{13} \mathrm{C}_{12}$-labeled PCB-208; $\mathrm{m} / \mathrm{z} 583.7$ and 585.7 for $\mathrm{Cl}_{10}$-DP; $\mathrm{m} / \mathrm{z} 617.7$ and 619.7 for $\mathrm{Cl}_{11}$-DP; $m / z 651.7$ and 653.7 for syn-DP and anti-DP; and $m / z 661.7$ and 663.7 for ${ }^{13} \mathrm{C}_{10}$-labeled syn-DP and ${ }^{13} \mathrm{C}_{10}$-labeled anti-DP.

The gravimetric method was used for lipid determination in milk, and the colorimetric method based on the sulfo-phospho-vanillin reaction was used for serum lipid determination (Aylward et al., 2003; Xian et al., 2011).

\subsection{Quality control}

The identification of DP congeners was based on their retention time and the isotopic ratios of the monitored ions relative to the congener standards. This quantitative determination incorporated an internal standard method using a calibration curve with six concentration levels. In addition, ${ }^{13} \mathrm{C}_{10}$ anti-DP was used as the internal standard for $\mathrm{Cl}_{10}$-DP, $\mathrm{Cl}_{11}$-DP and anti-DP, and ${ }^{13} \mathrm{C}_{10}$ syn-DP was used as the internal standard for syn-DP. Determination of recovery was made by quantification of target compounds $\left(\mathrm{Cl}_{10}\right.$-DP, $\mathrm{Cl}_{11}$-DP, anti-DP, and syn-DP) added to bovine serum and milk formula solution with a low $(0.05 \mathrm{ng})$ and high $(0.5 \mathrm{ng})$ amount of compounds. The average recovery of $\mathrm{Cl}_{10}$-DP, $\mathrm{Cl}_{11}$-DP, syn-DP and anti-DP ranged from $88.4 \%$ to $104.6 \%$ in serum and from $86.7 \%$ to $104.9 \%$ in milk formulas for the low $(n=3)$ and high spike trials $(n=3)$. The repeatability was assessed by analyzing three matrices replicates, and the relative standard deviation was $<10 \%$ for all compounds in milk or serum. The method detection limits (MDLs) were defined as the sample concentration of target compounds producing a chromatogram peak with a signal-to-noise ratio of 5 . Based on the volume/weight of samples (maternal serum: $5.0 \mathrm{~mL}$; breast milk: $3.0 \mathrm{~g}$ ), average lipid percentage and injection volume $(20 \mu \mathrm{L})$, MDLs in serum for $\mathrm{Cl}_{10}$-DP, $\mathrm{Cl}_{11}$-DP, syn-DP and anti-DP were $31.3,46.9,93.8$ and $78.1 \mathrm{pg} / \mathrm{g} \mathrm{lw}$, respectively, and 17.2, 22.9, 46.0 and $34.5 \mathrm{pg} / \mathrm{g} \mathrm{lw}$, respectively, in milk samples. In real sample analysis, the recoveries of the internal standards added to serum and breast milk before extraction were $60.1-97.2 \%$ for ${ }^{13} \mathrm{C}_{10}$ syn-DP and $57.9 \%-89.9 \%$ for ${ }^{13} \mathrm{C}_{10}$ anti-DP.

To ensure accuracy, method blanks (using solvents identical to those used for the actual samples) were included within each sample batch and run through complete extraction, cleanup and analysis procedures. Field blanks and field operation blanks were also subjected to the entire procedure. There were no detectable concentrations of DP and its dechlorinated analogs in these blank samples. Therefore, the results were not corrected by background levels.

\subsection{Data analysis}

All statistical analyses were performed using SPSS 13.0 statistical software (SPSS Inc., Chicago, IL, USA) and least-square linear regression was fitted in OriginPro8 SR0 software (www.OriginLab.com). The Kolmogorov-Smirnov test was used for normal testing of all continuous variables. The Differences in demographic factors were compared using the Pearson $\chi^{2}$ test. The Mann-Whitney U-test was used to compare differences in lipid weights and pollutant levels between the $R_{20}$ and $R_{3}$ groups. A $p$-value $<0.05$ was considered statistically significant. For chemicals with $<60 \%$ detection rate, statistical description was not calculated and reported because of the large uncertainty in the measurements. For chemicals with $>60 \%$ detection rate, when the peak of a chemical was not detected, the value obtained by dividing the MDL by 2 was used for statistical analysis.

\section{Results and discussion}

\subsection{Level of Dechlorane Plus and its dechlorinated analog}

Two stereoisomers of DP (syn-DP and anti-DP) and two dechlorinated analogs $\left(\mathrm{Cl}_{11}\right.$-DP and $\mathrm{Cl}_{10}$-DP) in breast milk and maternal serum samples were detected in the current study. Syn-DP and anti-DP were detected in all milk $(n=44)$ and serum samples $(n=45)$. The $\mathrm{Cl}_{11}$-DP detection frequency in breast milk and serum was $45 \%$ and $84 \%$, respectively. Among the dechlorinated analogs, $\mathrm{Cl}_{10}$-DP was not detected in all samples. These observations indicated that DP and its monodechlorinated analog could bioaccumulate in human serum and breast milk, and had become a widespread pollutant in the e-waste recycling site in Wenling of Taizhou region, China. The $\sum$ DPs refers to the sum of syn-DP and anti-DP. Comparison of the amount of syn-DP, $\mathrm{Cl}_{11}$-DP, anti-DP and $\sum$ DPs in breast milk and serum samples is shown in Table 2. We found that the arithmetic mean levels of syn-DP, anti-DP and $\sum$ DPs in the $R_{20}$ group were much higher than the median levels, demonstrating a skewed distribution of DP concentrations. For $\mathrm{Cl}_{11}$-DP, arithmetic mean serum levels in the $\mathrm{R}_{20}$ group were also significantly higher than the median levels. High levels of $\mathrm{Cl}_{11}$-DP were also found in some samples of breast milk, but because of the low detection rate (45\%), statistics were not performed and reported in Table 2. Significant differences in levels of DP and its monodechlorinated analog in serum were found between the $R_{20}$

Table 2

Concentration of DP and its monodechlorinated analog in breast milk and maternal serum (ng/g, lipid).

\begin{tabular}{|c|c|c|c|c|c|c|c|c|c|c|c|c|c|}
\hline & \multicolumn{6}{|c|}{$\mathrm{R}_{20}$ group } & \multicolumn{6}{|c|}{$\mathrm{R}_{3}$ group } & \multirow[t]{2}{*}{$p$-value } \\
\hline & Min. & Max. & Mean & Median & Geomean & SD & Min. & Max. & Mean & Median & Geomean & SD & \\
\hline \multicolumn{14}{|c|}{ Breast milk } \\
\hline syn-DP & 0.290 & 139.2 & 10.4 & 1.33 & 2.23 & 29.1 & 0.150 & 1.68 & 0.620 & 0.500 & 0.480 & 0.450 & $0.002^{* * a}$ \\
\hline $\mathrm{Cl}_{11}$-DP & $\mathrm{ND}^{\mathrm{b}}$ & 7.19 & - & - & - & 2.02 & $\mathrm{ND}^{\mathrm{b}}$ & 0.280 & - & - & - & - & $-^{c}$ \\
\hline anti-DP & 0.710 & 451 & 27.4 & 3.32 & 5.56 & 88.1 & 0.640 & 6.81 & 2.06 & 1.58 & 1.60 & 1.68 & $0.034^{* a}$ \\
\hline $\begin{array}{l}\sum D P s \\
\text { Serum }\end{array}$ & 1.01 & 590 & 37.7 & 4.46 & 7.88 & 117 & 0.830 & 8.05 & 2.67 & 2.19 & 2.12 & 2.06 & $0.004^{* * a}$ \\
\hline syn-DP & 0.560 & 278 & 25.4 & 2.79 & 4.88 & 66.9 & 0.370 & 3.18 & 1.29 & 0.960 & 1.04 & 0.900 & $0.000^{* * a}$ \\
\hline $\mathrm{Cl}_{11}$-DP & $\mathrm{ND}^{\mathrm{b}}$ & 14.9 & 1.18 & 0.25 & 0.34 & 2.81 & $\mathrm{ND}^{\mathrm{b}}$ & 0.450 & 0.15 & 0.110 & 0.110 & 0.120 & $0.025^{* a}$ \\
\hline anti-DP & 1.24 & 656 & 46.1 & 5.95 & 11.3 & 127 & 1.44 & 8.54 & 3.55 & 2.71 & 3.03 & 2.29 & $0.001^{* * a}$ \\
\hline$\sum \mathrm{DPs}$ & 1.80 & 900 & 71.5 & 8.64 & 16.4 & 186 & 1.84 & 11.6 & 4.84 & 4.02 & 4.13 & 3.11 & $0.001^{* * a}$ \\
\hline
\end{tabular}

* Significant at the 0.05 level (2-tailed).

** Significant at the 0.01 level (2-tailed).

a Mann-Whitney Test.

b $\mathrm{ND}<\mathrm{MDL}$

c No data due to low detection frequency in milk. 
and $\mathrm{R}_{3}$ group ( $p<0.05$, Table 2 ). In some cases, elevated DP levels in serums from the donors in the $\mathrm{R}_{20}$ group, such as the donors defined as p-004 (476 ng g ${ }^{-1} \mathrm{lw}$ ), p-010 (900 ng g-1 lw), p-018 (68.3 $\mathrm{ng} \mathrm{g}^{-1} \mathrm{lw}$ ) and $\mathrm{p}-031$ (415 $\mathrm{ng} \mathrm{g}^{-1} \mathrm{lw}$ ), were observed for a group of women living on the second floor of a building that was used for e-waste recycling activity on the first floor. This finding indicated that environmental contamination from e-waste activity strongly contributed to elevated DP and $\mathrm{Cl}_{11}$-DP levels in long-term Wenling residents.

There are limited reports on DP in human samples. There is only one published report on breast milk (Siddique et al., 2012) and one on human serum (Ren et al., 2009). The median $\sum D P$ concentration in breast milk in this study was 2-4-fold higher than that from the general population from two Canadian cities $\left(0.98 \mathrm{ng} \mathrm{g}^{-1}\right.$ lipid), which indicated an elevated DP exposure to residents living in the e-waste recycling area. However, Ren et al. reported that the median level of $\sum$ DPs in human serum was $42.6 \mathrm{ng} \mathrm{g}^{-1}$ lipid for workers from an e-waste recycling region and $13.7 \mathrm{ng} \mathrm{g}^{-1}$ lipid for residents from a control group in Guiyu, China (Ren et al., 2009). In our study, the median serum level of $\sum D P s$ from the $R_{20}$ group (8.64 $\mathrm{ng} \mathrm{g}^{-1}$ lipid) was approximately the 5 -fold lower than that in the exposure group, and was similar to the value of the control group in the study by Ren et al. This difference was possibly related to the selection of donors, who came from a population living in ewaste recycling sites in our study, but they were not directly participating in e-waste recycling operations. However, $\sum$ DPs levels found in the serums of two donors in this study, defined as p010 (900 $\mathrm{ng} \mathrm{g}^{-1} \mathrm{lw}$ ) and p-004 (476 $\mathrm{ng} \mathrm{g}^{-1} \mathrm{lw}$ ), were above the maximum value of $\sum$ DPs (465 $\mathrm{ng} \mathrm{g}^{-1}$ lipid) in serum reported by Ren et al. $\mathrm{Cl}_{11}$-DP levels found in the serum from p-010 and p-004 was $14.9 \mathrm{ng} \mathrm{g}^{-1} \mathrm{lw}$ and $6.07 \mathrm{ng} \mathrm{g}^{-1} \mathrm{lw}$, respectively. The monodechlorinated compound was also found in Ren et al. (2009), but it was unquantified.

Generally, PCBs and PBDE concentrations in human tissues from the contamination area in Taizhou range from dozens to hundreds ng $\mathrm{g}^{-1} \mathrm{lw}$ (Zhao et al., 2007, 2010; Leung et al., 2010). In a study in 2006 on $\sum{ }_{5}$ PCBs (CB-105, 118, 153, 183, and 180) in blood from two typical e-waste recycling sites in Taizhou (Luqiao and Wenling), the arithmetic mean level was $204.2 \mathrm{ng} \mathrm{g}^{-1} \mathrm{lw}$ for Luqiao and $83.8 \mathrm{ng} \mathrm{g}^{-1} \mathrm{lw}$ for Wenling, and $\sum_{8}$ PBDEs (BDE-28, 47, 99, 100, 153, 154,180 , and 209) were $117.58 \mathrm{ng} \mathrm{g}^{-1} \mathrm{lw}$ for Luqiao and $357.44 \mathrm{ng} \mathrm{g}^{-1} \mathrm{lw}$ for Wenling (Zhao et al., 2010). For breast milk, $\sum_{23}$ PCBs (CB-28, 52, 99, 101, 128, 138, 153, 170, 180, 183, 187, 77, 81, $105,114,118,123,126,156,157,167,169,189)$ were $206.05 \mathrm{ng} \mathrm{g}^{-1} \mathrm{lw}$ for Pingqiao and $359.03 \mathrm{ng} \mathrm{g}^{-1} \mathrm{lw}$ for Luqiao (Zhao et al., 2007). The arithmetic mean level of $\sum{ }_{36}$ PBDEs (BDE-7, 8, 10, 11, 12, 13, 15, 17, $25,28,30,32,33,35,37,47,49,66,71,75,77,85,99,100,116,118$, $119,126,138,153,154,155,166,181,183,190)$ was found to be $117 \mathrm{ng} \mathrm{g}^{-1}$ lw in Taizhou (Leung et al., 2010). Dechlorane Plus levels found in the current study were relatively low compared with PCBs/PBDEs data from human exposure in Taizhou region mentioned above.

\subsection{DP partitioning in blood and milk}

The ratio of milk/serum was used to examine the partitioning relationship of DP between breast milk and maternal serum, and it referred to the ratio of the lipid-adjusted levels detected in milk and serum from the same woman. We showed that the partitioning in milk/serum was mainly related to the physicochemical properties of compounds, including differences in lipophilicity, molecular size and weight (Lakind, 2007; Wittsiepe et al., 2007) and degree of chlorination (Van Oostdam et al., 2005). Additionally, there was no difference in average value of the milk/serum ratios of syn-DP and anti-DP between the $R_{20}$ and $R_{3}$ groups. Therefore, demographic factors were excluded and the milk/serum ratios of DP in all milk and blood samples from the same woman were analyzed. In our study, milk/serum ratio calculations for the DP chemicals only included data from individuals who had both milk and serum sample concentrations above the MDLs.

The milk/serum ratio varied from 0.07 to 2.25 (median: 0.41 ) for syn-DP and from 0.09 to 2.22 (median: 0.44) for anti-DP, that of $\mathrm{Cl}_{11}$-DP was excluded because of low detection in milk. Spearman rank association analyses revealed a significant association between milk and serum lipid-adjusted DP concentrations ( $n=40$, $p<0.001$ ). Therefore, a linear equation was further fitted by least squares for the prediction of DP levels in milk or serum. The equation of each chemical was:

$\log ($ milk $)=\log ($ serum $)+\log (b)$

where estimated $b$ was the predicted milk/serum partition coefficient of each chemical (Zhu et al., 2007). Log transformation of DP levels between serum and milk samples from the same woman is shown in Fig. 1A and Fig. 1B $(n=40)$. In the predicted equation, log (b) of syn-DP and anti-DP was estimated to be -0.37 and -0.33 , respectively. Therefore, the predicted milk/serum partition
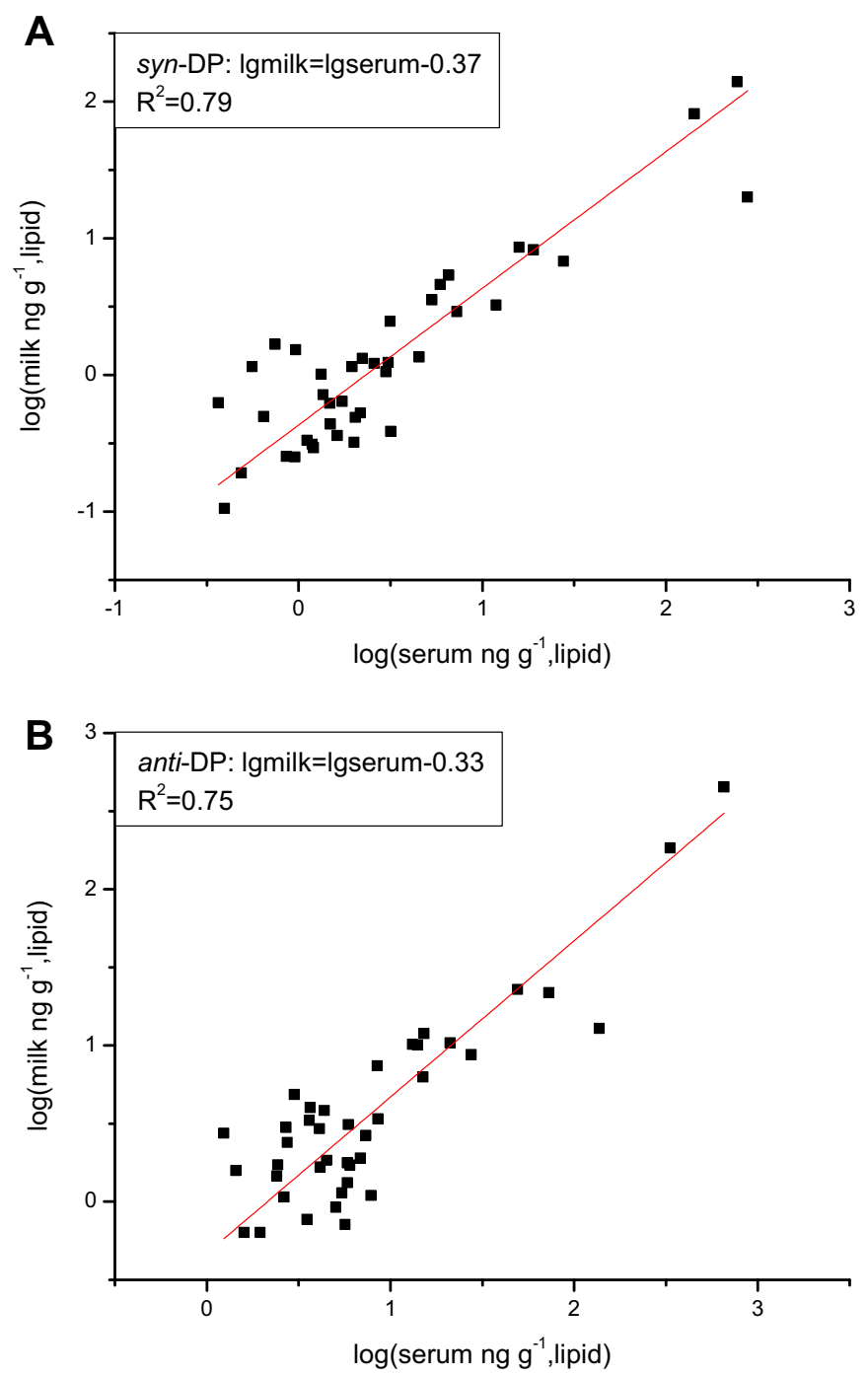

Fig. 1. Relatioship between lipid-adjusted milk/serum concentration of two DP isomers from the same woman. (A) syn-DP, (B) anti-DP $(n=40)$. 
coefficient of syn-DP and anti-DP was approximately $0.43\left(10^{-0.37}\right)$ and $0.47\left(10^{-0.33}\right)$, respectively. Although the predicted milk/serum partition coefficient displayed a slightly higher transfer rate of antiDP from blood to milk, the milk/serum ratios of syn-DP and anti-DP were not significantly different $(p=0.567)$ by Mann-Whitney Utest, suggesting similar stereoselective DP bio-accumulation profile in milk and blood. The milk/serum partition coefficient of syn-DP and anti-DP was $<1.0$ ( $p<0.001$ for breast milk and serum), which indicated preferential partitioning of DP in the blood compared with breast milk.

Breast milk lipid concentrations of persistent lipophilic compounds generally reflect blood lipid levels (Aylward et al., 2003), and the partition coefficient/ratio between breast milk and serum is probably different from one compound to another. For example, on the lipid-adjusted basis, the values of OCPs (including p, $\mathrm{p}^{\prime}$-DDE and p, $\mathrm{p}^{\prime}$-DDT), PCBs (including CB-118, 138-158, 146, 153, 170, 180, 187, 74 and 99), and PBDEs (including BDE-28, 47, 99 and $100)$ are $>1.0$, and those of PCB-126 and BDE-153 are approximately equal to 1.0 , while those of $1,2,3,6,7,8-\mathrm{HxCDD}, 1,2,3,6,7,8$ HpCDD, 1,2,3,6,7,8-HpCDF and OCDD are significantly $<1.0$ (LaKind et al., 2009). Wittsiepe et al. (2007) reported that higher chlorinated PCDD/F- and PCB-congeners were found in 2-4-fold higher lipid-adjusted concentrations in blood than milk, and the lipid-adjusted concentrations of lower chlorinated PCB-congeners were up to 2-fold higher in milk in relation to blood. Schecter et al. (2010) have published data suggesting the BDE congenerspecific partitioning occurs in blood and milk of the same women where higher brominated BDEs are higher level in blood lipids than milk lipids. Among these legacy chemicals such as PCBs, PBDEs and $\mathrm{PCDDs} / \mathrm{Fs}$, it is considered that there is preferential partitioning into milk for lower molecular weight, smaller molecular diameter, smaller $K_{\text {ow }}$ and lower chlorinated/brominated chemicals (Wittsiepe et al., 2007; LaKind et al., 2009; Schecter et al., 2010). The molecular mass of DP is 653.68 , while $K_{\text {ow }}$ of the DP technical product is approximately 9.3 with 12 chlorine atoms (OxyChem., 2010), which probably decreases the membrane permeability and might be responsible for the low DP milk/serum partition coefficient.

Aylward et al. thought that it was critical that paired samples be collected as close in time as possible to determine accurate milk/ serum partition coefficient of an environmental chemical (Aylward et al., 2003). In our study, the serum was collected at delivery and breast milk was collected 2-7 days after delivery. Samples being taken 2-7 days apart probably led to a decrease in accuracy in predicting the DP milk/serum partition coefficient.

\subsection{Anti-DP fractional abundance}

The anti-DP fractional abundance $\left(f_{\text {anti }}\right)$ is used to represent the profile characteristic of DP and defined as the amount of anti-DP in total DP. Commercial DP products are classified into three industrial forms based on particle size, as they do not differ in composition. However, reported DP $f_{\text {anti }}$ in commercial products are not always consistent, because of different lots and manufacturers (Hoh et al., 2006). For example, the value reported by Tomy et al. for a DP standard (Oxychem, Occidental Petroleum Corporation, Los Angeles, CA, USA) was 0.65 (Tomy et al., 2007), whereas $f_{\text {anti }}$ of the technical DP standard from Cambridge Isotope Laboratories (USA) was reported by Kang et al. as 0.75 (Kang et al., 2010). In our laboratory, the ratio of technical product from Jiangsu Anpon Electrochemical Co., Ltd. was detected as $0.7859 \pm 0.012$ by GC$\mathrm{NCI}-\mathrm{MS}$ and as $0.7720 \pm 0.005$ by high resolution gas chromatography-electron impact-high resolution mass spectrometry (HRGC-EI-HRMS) (arithmetic mean: 0.78), which were close to the value of the Cambridge standard. Therefore, DP $f_{\text {anti }}$ in commercial products may range from 0.60 to 0.80 .

In this study, $f_{\text {anti }}$ in $90 \%$ breast milk samples and $91 \%$ serum samples from the $\mathrm{R}_{20}$ group were in the range of $0.6-0.8$, and the arithmetic mean of $f_{\text {anti }}$ was calculated as 0.71 and 0.70 in breast milk and serum samples, respectively. For the $\mathrm{R}_{3}$ group, $f_{\text {anti }}$ in $57 \%$ breast milk samples and $83 \%$ serum samples varied from 0.6 to 0.8 , and the arithmetic mean of $f_{\text {anti }}$ was calculated as 0.76 and 0.75 in breast milk and serum samples, respectively. It appeared that $f_{\text {anti }}$ in most breast milk and serum samples from two groups was in the range of $f_{\text {anti }}$ reported in commercial products (0.60.8 ). However, compared with the DP products from Cambridge Isotope Laboratories (0.75) and Jiangsu Anpon Electrochemical (0.78), $f_{\text {anti }}$ from the $R_{20}$ group was significantly lower in breast milk ( $p=0.007$ and $<0.001$, respectively) and serum $(p=0.001$ and $<0.001$ respectively). In the $\mathrm{R}_{3}$ group, no differences in $f_{\text {anti }}$ were found compared with the DP products from these two other companies in milk ( $p=0.643$ and 0.360 , respectively) or serum ( $p=0.902$ and 0.155 , respectively). Ren et al. speculated that the burning process during e-waste recycling activity might induce significantly low serum $f_{\text {anti }}$ in residents of polluted communities (Ren et al., 2009). Although we found significant differences in $f_{\text {anti }}$ in the $R_{20}$ group, a definitive conclusion on selective DP bioaccumulation in breast milk or serum could not be drawn because of possible low $f_{\text {anti }}$ from the environment of the study population.

In both groups, breast milk $f_{\text {anti }}$ was similar to that detected in maternal serum from the same woman. Clear stereoselective bioaccumulation potentials between DP isomers (syn-DP and antiDP) have been observed in juvenile rainbow trout (Tomy et al., 2008) and hepatic tissue of domestic chickens (Brock et al., 2010; Crump et al., 2011). Preferential distribution of syn-DP in the liver and a high affinity of anti-DP to brain tissue were also found in fish from a natural pond at an e-waste recycling site in South China (Zhang et al., 2011). However, stereoselective DP bioaccumulation in terrestrial biota and humans has not been fully confirmed (Ren et al., 2009; Xian et al., 2011; Siddique et al., 2012). The similar $f_{\text {anti }}$ in milk and serum from the same woman was found in this study, appearing to indicate no occurrence of stereoselective DP bio-accumulation during the DP transport from blood to breast milk in human. Further research on DP in human tissues is necessary to determine stereoselective DP bioaccumulation. Notably, serum $f_{\text {anti }}\left(0.70\right.$ for the $R_{20}$ group and 0.75 for the $R_{3}$ group) in our study, was higher than data ( 0.53 in Guiyu and 0.64 in Haojiang) reported by Ren et al. (2009). Further research is also required to investigate this disparity between studies.

\section{Conclusions}

In conclusion, our study extends the knowledge that DP and its monodechlorinated analog can bio-accumulate in maternal blood and may postnatally expose the breastfed infant via breast milk. We found a relatively consistent and stable partitioning relationship between milk and serum concentrations of syn-DP or anti-DP, on a lipid-adjusted basis. This similar anti-DP fractional abundance in milk and serum appeared to indicate no occurrence of stereoselective DP bio-accumulation during the DP transport from blood to breast milk in human. Exposure from e-waste recycling activity was a dominant factor affecting DP levels in the study population. Further research is required on tissue distribution, stereoselective bio-accumulation, and health risk assessment of DP in humans, especially for infants living in e-waste recycling sites. 


\section{Acknowledgments}

This work was funded by the National Natural Science Foundation of China (20877092, 21177152 and 21107122).

\section{References}

Aylward, L.L., Hays, S.M., LaKind, J.S., Ryan, J.J., 2003. Rapid communication: partitioning of persistent lipophilic compounds, including dioxins, between human milk lipid and blood lipid: an initial assessment. J. Toxicol. Environ. Health-Part A $66,1-5$.

Brock, W.J., Schroeder, R.E., McKnight, C.A., VanSteenhouse, J.L., Nyberg, J.M., 2010. Oral repeat dose and reproductive toxicity of the chlorinated flame retardant dechlorane plus. Int. J. Toxicol. 29, 582-593.

Chan, J.K.Y., Xing, G.H., Xu, Y., Liang, Y., Chen, L.X., Wu, S.C., Wong, C.K.C., Leung, C.K.M., Wong, M.H., 2007. Body loadings and health risk assessment of polychlorinated dibenzo-p-dioxins and dibenzofurans at an intensive electronic waste recycling site in China. Environ. Sci. Technol. 41, 7668-7674.

Commission, S.E., 2011. The European Commission Report on Potential Alternatives to Deca-BDE. http://ecb.jrc.ec.europa.eu/documents/Existing-Chemicals/Review_on production_process_of_decaBDE (accessed 16.01.12.).

Crump, D., Chiu, S., Gauthier, L.T., Hickey, N.J., Letcher, R.J., Kennedy, S.W., 2011. The effects of dechlorane plus on toxicity and mRNA expression in chicken embryos: a comparison of in vitro and in ovo approaches. Comp. Biochem. Physiol. C-Toxicol. Pharmacol. 154, 129-134.

Gauthier, L.T., Letcher, R.J., 2009. Isomers of dechlorane plus flame retardant in the eggs of herring gulls (Larus argentatus) from the Laurentian Great Lakes of North America: temporal changes and spatial distribution. Chemosphere 75, 115-120.

Hoh, E., Zhu, L.Y., Hites, R.A., 2006. Dechlorane plus, a chlorinated flame retardant, in the Great Lakes. Environ. Sci. Technol. 40, 1184-1189.

Jaraczewska, K., Lulek, J., Covaci, A., Voorspoels, S., Kaluba-Skotarczak, A., Drews, K. Schepens, P., 2006. Distribution of polychlorinated biphenyls, organochlorine pesticides and polybrominated diphenyl ethers in human umbilical cord serum, maternal serum and milk from Wielkopolska region, Poland. Sci. Total Environ. $372,20-31$.

Kang, J.-H., Kim, J.-C., Jin, G.-Z., Park, H., Baek, S.-Y., Chang, Y.-S., 2010. Detection of dechlorane plus in fish from urban-industrial rivers. Chemosphere 79 , $850-854$.

Lakind, J.S., 2007. Recent global trends and physiologic origins of dioxins and furans in human milk. J. Expo. Sci. Environ. Epidemiol. 17, 510-524.

LaKind, J.S., Berlin Jr., C.M., Sjodin, A., Turner, W., Wang, R.Y., Needham, L.L. Paul, I.M., Stokes, J.L., Naiman, D.Q., Patterson Jr., D.G., 2009. Do human milk concentrations of persistent organic chemicals really decline during lactation? Chemical concentrations during lactation and milk/serum partitioning. Environ. Health Perspect. 117, 1625-1631.

Leung, A.O., Chan, J.K., Xing, G.H., Xu, Y., Wu, S.C., Wong, C.K., Leung, C.K., Wong, M.H., 2010. Body burdens of polybrominated diphenyl ethers in childbearing-aged women at an intensive electronic-waste recycling site in China. Environ. Sci. Pollut. Res. Int. 17, 1300-1313.

Ni, H.-G., Zeng, H., Tao, S., Zeng, E.Y., 2010. Environmental and human exposure to persistent halogenated compounds derived from e-waste in China. Environ. Toxicol. Chem. 29, 1237-1247.
OxyChem., 2010. Dechlorane Plus Handbook [EB/OL]. http: //www. oxy. com /OurBusinesses/chemicals/Documents/ dechlorane-plus/ dechlorane-plus. pdf (24.06.10.).

Ren, G., Yu, Z., Ma, S., Li, H., Peng, P., Sheng, G., Fu, J., 2009. Determination of dechlorane plus in serum from electronics dismantling workers in South China. Environ. Sci. Technol. 43, 9453-9457.

Schecter, A., Colacino, J., Sjodin, A., Needham, L., Birnbaum, L., 2010. Partitioning of polybrominated diphenyl ethers (PBDEs) in serum and milk from the same mothers. Chemosphere 78, 1279-1284.

Siddique, S., Xian, Q.M., Abdelouahab, N., Takser, L., Phillips, S.P., Feng, Y.L., Wang, B., Zhu, J.P., 2012. Levels of dechlorane plus and polybrominated diphenylethers in human milk in two Canadian cities. Environ. Int. 39, 50-55.

Sverko, E., Tomy, G.T., Reiner, E.J., Li, Y.F., McCarry, B.E., Arnot, J.A., Law, R.J., Hites, R.A., 2011. Dechlorane plus and related compounds in the environment: a review. Environ. Sci. Technol. 45, 5088-5098.

Tomy, G.T., Pleskach, K., Ismail, N., Whittle, D.M., Helm, P.A., Sverko, E., Zaruk, D., Marvin, C.H., 2007. Isomers of dechlorane plus in Lake Winnipeg and Lake Ontario food webs. Environ. Sci. Technol. 41, 2249-2254.

Tomy, G.T., Thomas, C.R., Zidane, T.M., Murison, K.E., Pleskach, K., Hare, J. Arsenault, G., Marvin, C.H., Sverko, E., 2008. Examination of isomer specific bioaccumulation parameters and potential in vivo hepatic metabolites of synand anti-dechlorane plus isomers in juvenile rainbow trout (Oncorhynchus mykiss). Environ. Sci. Technol. 42, 5562-5567.

Van Oostdam, J., Donaldson, S.G., Feeley, M., Arnold, D., Ayotte, P., Bondy, G., Chan, L., Dewaily, E., Furgal, C.M., Kuhnlein, H., Loring, E., Muckle, G., Myles, E., Receveur, O., Tracy, B., Gill, U., Kalhok, S., 2005. Human health implications of environmental contaminants in Arctic Canada: a review. Sci. Total Environ. 351, 165-246.

Verreault, J., Gabrielsen, G.V., Chu, S.G., Muir, D.C.G., Andersen, M., Hamaed, A., Letcher, R.J., 2005. Flame retardants and methoxylated and hydroxylated polybrominated diphenyl ethers in two Norwegian Arctic top predators: glaucous gulls and polar bears. Environ. Sci. Technol. 39, 6021-6028.

Wittsiepe, J., Fuerst, P., Schrey, P., Lemm, F., Kraft, M., Eberwein, G., Winneke, G., Wilhelm, M., 2007. PCDD/F and dioxin-like PCB in human blood and milk from German mothers. Chemosphere 67, S286-S294.

Wu, J.-P., Zhang, Y., Luo, X.-J., Wang, J., Chen, S.-J., Guan, Y.-T., Mai, B.-X., 2010. Isomer-specific bioaccumulation and trophic transfer of dechlorane plus in the freshwater food web from a highly contaminated site, South China. Environ. Sci. Technol. 44, 606-611.

Xian, Q., Siddique, S., Li, T., Feng, Y.-l., Takser, L., Zhu, J., 2011. Sources and environmental behavior of dechlorane plus - a review. Environ. Int. 37, 1273-1284.

Zhang, Y. Wu, J.P. Luo, X.J., Wang J., Chen, S.J., Mai, B.X., 2011. Tissue distribution of dechlorane plus and its dechlorinated analogs in contaminated fish: high affinity to the brain for anti-DP. Environ. Pollut. 159, 3647-3652.

Zhao, G., Xu, Y., Li, W., Han, G., Ling, B., 2007. PCBs and OCPs in human milk and selected foods from Luqiao and Pingqiao in Zhejiang, China. Sci. Total Environ. 378, 281-292.

Zhao, X.-R., Qin, Z.-F., Yang, Z.-Z., Zhao, Q., Zhao, Y.-X., Qin, X.-F., Zhang, Y.-C., Ruan, X.-L., Zhang, Y.-F., Xu, X.-B., 2010. Dual body burdens of polychlorinated biphenyls and polybrominated diphenyl ethers among local residents in an ewaste recycling region in Southeast China. Chemosphere 78, 659-666.

Zheng, J., Wang, J., Luo, X.-J., Tian, M., He, L.-Y., Yuan, J.-G., Mai, B.-X., Yang, Z.-Y., 2010. Dechlorane plus in human hair from an e-waste recycling area in South China: comparison with dust. Environ. Sci. Technol. 44, 9298-9303.

Zhu, J., Feng, Y.-L., Shoeib, M., 2007. Detection of dechlorane plus in residential indoor dust in the city of Ottawa, Canada. Environ. Sci. Technol. 41, 7694-7698. 